\title{
High percent body fat mass predicts lower risk of cardiac events in patients with heart failure: an explanation of the obesity paradox
}

Katsuhiko Ohori ${ }^{1,2}$, Toshiyuki Yano ${ }^{1 *}$ (D), Satoshi Katano ${ }^{3}$, Hidemichi Kouzu', Suguru Honma ${ }^{3}$, Kanako Shimomura ${ }^{3}$, Takuya Inoue ${ }^{3}$, Yuhei Takamura ${ }^{3}$, Ryohei Nagaoka ${ }^{3}$, Masayuki Koyama ${ }^{1,4}$, Nobutaka Nagano', Takefumi Fujito', Ryo Nishikawa', Tomoyuki Ishigo ${ }^{5}$, Ayako Watanabe ${ }^{6}$, Akiyoshi Hashimoto ${ }^{1,7}$ and Tetsuji Miura ${ }^{1}$

\begin{abstract}
Background: Although high body mass index (BMI) is a risk factor of heart failure (HF), HF patients with a higher BMI had a lower mortality rate than that in HF patients with normal or lower BMI, a phenomenon that has been termed the "obesity paradox". However, the relationship between body composition, i.e., fat or muscle mass, and clinical outcome in HF remains unclear.

Methods: We retrospectively analyzed data for 198 consecutive HF patients (76 years of age; males, 49\%). Patients who were admitted to our institute for diagnosis and management of HF and received a dual-energy $X$-ray absorptiometry scan were included regardless of left ventricular ejection fraction (LVEF) categories. Muscle wasting was defined as appendicular skeletal muscle mass index $<7.0 \mathrm{~kg} / \mathrm{m}^{2}$ in males and $<5.4 \mathrm{~kg} / \mathrm{m}^{2}$ in females. Increased percent body fat mass (increased FM) was defined as percent body fat $>25 \%$ in males and $>30 \%$ in females.
\end{abstract}

Results: The median age of the patients was 76 years (interquartile range [IQR], 67-82 years) and $49 \%$ of them were male. The median LVEF was 47\% (IQR, 33-63\%) and 33\% of the patients had heart failure with reduced ejection fraction. Increased FM and muscle wasting were observed in 58 and $67 \%$ of the enrolled patients, respectively. During a 180-day follow-up period, 32 patients (16\%) had cardiac events defined as cardiac death or readmission by worsening HF or arrhythmia. Kaplan-Meier survival curves showed that patients with increased FM had a lower cardiac event rate than did patients without increased FM (11.4\% vs. $22.6 \%, p=0.03)$. Kaplan-Meier curves of cardiac event rates did not differ between patients with and those without muscle wasting (16.5\% vs. $15.4 \%, p=0.93)$. In multivariate Cox regression analyses, increased FM was independently associated with lower cardiac event rates (hazard ratio: 0.45, 95\% confidence interval: 0.22-0.93) after adjustment for age, sex, diabetes, muscle wasting, and renal function.

Conclusions: High percent body fat mass is associated with lower risk of short-term cardiac events in HF patients.

Keywords: Heart failure, Body mass index, Obesity, Skeletal muscle, Fat

\footnotetext{
*Correspondence: oltomwaits55@gmail.com

'Department of Cardiovascular, Renal and Metabolic Medicine, Sapporo

Medical University School of Medicine, South-1, West-16, Chuo-ku, Sapporo 060-8543, Japan

Full list of author information is available at the end of the article
}

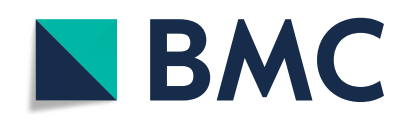

(c) The Author(s). 2021 Open Access This article is licensed under a Creative Commons Attribution 4.0 International License, which permits use, sharing, adaptation, distribution and reproduction in any medium or format, as long as you give appropriate credit to the original author(s) and the source, provide a link to the Creative Commons licence, and indicate if changes were made. The images or other third party material in this article are included in the article's Creative Commons licence, unless indicated otherwise in a credit line to the material. If material is not included in the article's Creative Commons licence and your intended use is not permitted by statutory regulation or exceeds the permitted use, you will need to obtain permission directly from the copyright holder. To view a copy of this licence, visit http://creativecommons.org/licenses/by/4.0/ The Creative Commons Public Domain Dedication waiver (http://creativecommons.org/publicdomain/zero/1.0/) applies to the data made available in this article, unless otherwise stated in a credit line to the data. 


\section{Background}

Body mass index (BMI) is an easily measurable and quantitative anthropometric indicator of body mass and nutritional status, and it is widely used for the definition and classification of obesity. It has been established that obesity, generally defined as a BMI $\geq 25 \mathrm{~kg} / \mathrm{m}^{2}$, is an independent risk factor of incident chronic diseases including hypertension, type 2 diabetes mellitus, cancer, and heart failure (HF) [1-3]. However, it has been shown that mortality is not proportionally increased with BMI-defined obesity. Results from epidemiological studies suggest that overweight (BMI, $25.0-29.9 \mathrm{~kg} / \mathrm{m}^{2}$ ) or class I obesity (BMI, $30-34.9 \mathrm{~kg} / \mathrm{m}^{2}$ ) is not associated with a worse clinical outcome or is associated even with a favorable outcome in the study population [4-6]. That is the case in HF patients; HF patients with a higher BMI had a lower mortality rate than that in HF patients with normal or lower BMI, a phenomenon that has been termed the "obesity paradox" [2, 3, 7-10]. In addition, a U-shaped relationship between BMI and mortality has been reported for both patients with heart failure with reduced ejection fraction (HFrEF) and patients with heart failure with preserved ejection fraction (HFpEF) $[9,10]$. However, the reason for this complex relationship between BMI and mortality in HF patients has not been fully elucidated.

Cachexia is a hallmark in the advanced stage of chronic diseases including HF and is defined as involuntary loss of at least $5 \%$ of non-edematous body weight [11]. A pioneering study in this field by Anker et al. showed that the presence of cachexia is an independent predictor for mortality even after adjustment for age, exercise capacity, and severity of HF [12]. Body composition analyses by the use of dualenergy X-ray absorptiometry (DEXA) revealed that cachexic patients had reduced fat mass, reduced lean mass (muscle mass), and reduced bone mineral content [13]. Thus, a plausible explanation of the obesity paradox is that high BMI increases the risk of HF development, while HFinduced cachexia per se is associated with increased mortality. However, the natural history of each composition of the body (i.e., fat, muscle mass, bone mineral content) during progression of $\mathrm{HF}$ and the impact of the composition on prognosis of HF patients remain to be elucidated. In the present study, we used a DEXA scan, the best technique for analyzing body composition in research studies [14], to examine the relationships between fat and muscle masses and clinical outcome in HF patients.

\section{Methods}

This study was approved by the Clinical Investigation Ethics Committee of Sapporo Medical University Hospital (Number 302-104). This study was carried out by the opt-out method of our hospital website. Informed consent was obtained in the form of opt-out on the website.

\section{Study subjects}

This study was conducted in strict adherence with the principles of the Declaration of Helsinki. This study was a single center, retrospective, and observational study. Consecutive patients who were admitted to our institute for diagnosis and management of HF during the period from January 1, 2016 to October 31, 2018 were retrospectively enrolled. HF was diagnosed according to Japanese Circulation Society/Japanese Heart Failure Society Guidelines for Heart Failure [15]. Patients who were admitted for acute decompensation heart failure were also included. DEXA measurements were performed after their symptoms were relieved to New York Heart Association (NYHA) functional class III in patients who had NYHA functional class IV symptoms at the time of admission. We excluded patients who had in-hospital death and were transferred to other hospitals at the time of discharge from our hospital. For patients who underwent multiple DEXA measurements for assessment of body composition during hospitalization, the last data set was used for analysis.

\section{DEXA measurements}

Body composition analyses were performed as previously reported [16]. Whole and regional fat/lean masses of patients were analyzed by using the Horizon DXA System (HOLOGIC, Waltham, MA, USA) and lean mass was defined as an index of muscle mass. Increased percent body fat mass (increased FM) was defined as DEXAmeasured percent body fat mass $>25 \%$ in males and $>$ $30 \%$ in females according to the results of a Japanese epidemiological study showing the association of percent body fat mass with prevalence rates of cardiac and metabolic diseases [17]. Appendicular skeletal muscle mass (ASM) was calculated as the sum of bone-free lean masses in the arms and legs. ASM index (ASMI) was defined as ASM/height ${ }^{2}$. The cut-off values of ASMI for muscle wasting were $<7.00 \mathrm{~kg} / \mathrm{m}^{2}$ in males and $<5.40$ $\mathrm{kg} / \mathrm{m}^{2}$ in females according to the criteria of the Asian Work Group for Sarcopenia [18].

\section{Laboratory data and echocardiography}

Measurement of laboratory data (serum albumin, hemoglobin, creatinine, estimated glomerular filtration rate [eGFR], fasting plasma glucose, insulin, total cholesterol, low density lipoprotein cholesterol, high density lipoprotein cholesterol, triglyceride and $\mathrm{N}$ terminal pro B-type natriuretic peptide [NT-proBNP]) and echocardiographic analyses were performed as previously reported [16]. The left ventricular ejection fraction (LVEF) was measured by the modified Simpson method. 


\section{Clinical endpoint}

A cardiac event was defined as cardiac death or unscheduled readmission by worsening HF or arrhythmia. Data for clinical endpoints during a period of 180 days after hospital discharge in the patients were collected from the medical records. Intervals between outpatient clinic visits were $4 \sim 8$ weeks depending on the patients.

\section{Statistical analysis}

Data are presented as means \pm standard deviation, medians (interquartile range [IQR]), or percentages for variables. Differences in continuous variables between patients with and those without increased FM or muscle wasting were tested by the chi-square test or the MannWhitney U test. Differences in categorical variables between patients with and those without increased FM or muscle wasting were examined by the chi-square test. Survival curves were calculated by the Kaplan-Meier method, and statistical significance of differences between the curves was assessed by log-rank statistics. Univariate and multivariate Cox proportional hazard models were used to determine the contribution of increased FM or muscle wasting to cardiac event rates. A probability value of $<0.05$ was adopted as the critical level of statistical significance. Statistical analysis was performed using $\mathrm{R}$ version 3.5.2 ( $\mathrm{R}$ Foundation for Statistical Computing, Vienna, Austria).

\section{Results}

\section{Baseline characteristics}

Of 244 patients screened, 198 patients met inclusion criteria without exclusion criteria and contributed to the analyses. Baseline clinical characteristics of the patients are shown in Table 1 . The median age of the patients was 76 years (IQR, 67-82 years) and $49 \%$ of them were male. The median BMI of the patients was $21.8 \mathrm{~kg} / \mathrm{m}^{2}$. Forty-four percent of the patients were classified as NYHA functional class III. The median left ventricular ejection fraction (LVEF) was 47\% (IQR, 33-63\%) and $33 \%$ of the patients had HFrEF. Hypertension, dyslipidemia, diabetes and chronic kidney disease (CKD) were present in $70,52,38$ and $50 \%$ of the patients, respectively. The most frequent etiology of HF was cardiomyopathy $(37 \%)$, followed by valvular heart disease (29\%) and ischemic heart disease (19\%).

Increased FM and muscle wasting were observed in 58 and $67 \%$ of the enrolled patients, respectively. As shown in Table 1, there was no significant difference in age or gender between patients with and those without increased FM or muscle wasting. As expected, BMI level was higher in patients with increased FM than in those without increased FM, and patients with muscle wasting had lower BMI than did patients without muscle wasting. The proportion of patients with increased FM
(Fig. 1a) and the proportion of patients with muscle wasting (Fig. 1b) in each BMI-based obesity categories are shown in Fig. 1. This figure clearly indicates that the presence of increased FM or muscle wasting in each patient cannot be predicted by BMI alone.

\section{Comparison of groups with and without increased FM}

In patients with increased FM, NYHA functional class III symptoms tended to be less frequent (38\% vs 52\%), the proportion of patients with hypertension (76\% vs. $61 \%$ ) and dyslipidemia (62\% vs. $38 \%$ ) were significantly higher, and loop diuretics (54\% vs. $73 \%$ ) were less frequently prescribed compared with those in patients without increased FM (Table 1). Plasma albumin and creatinine levels were similar in patients with and those without increased FM. However, plasma insulin and triglyceride levels were higher and levels of high density lipoprotein cholesterol and NT-proBNP were lower in patients with increased FM than in patients without increased FM (Table 2).

\section{Comparison of groups with and without muscle wasting}

In patients with muscle wasting, NYHA functional class III symptoms were more frequent (53\% vs. 26\%), and the proportion of patients with diabetes (45\% vs. $25 \%)$ and patients on mineralocorticoid receptor antagonists $(53 \%$ vs. $34 \%$ ) were higher than those in patients without muscle wasting. Proportions of etiologies of HF were also different between patients with and without muscle wasting (Table 1). While plasma albumin and creatinine levels were similar in patients with and those without muscle wasting, plasma NT-proBNP level was significantly higher in patients with muscle wasting.

\section{Impacts of increased FM and muscle wasting on cardiac event rates}

During a 180-day follow-up period, 32 patients (16\%) had cardiac events. Kaplan-Meier survival curves showed that patients with increased FM had a significantly lower cardiac event rate than did patients without increased FM $(11.4 \%$ vs. $22.6 \%, p=0.03$, Fig. 2a). On the other hand, there was no difference in cardiac event rates between patients with muscle wasting and those without muscle wasting ( $16.5 \%$ vs. $15.4 \%, p=0.93$, Fig. $2 b)$. In addition, presence of muscle wasting had no effects on cardiac event rates also in HF patients with increased FM (Fig. 3). In multivariate Cox-proportional hazard analyses that were adjusted for age, sex, diabetes, and renal function, increased FM was independently associated with lower cardiac event rate (hazard ratio: 0.45, 95\% confidence interval: $0.22-0.93$, Table 3 ). The independent association between increased FM and cardiac event rate was lost by inclusion of NT-proBNP level and NYHA functional class III, but not LVEF, into the Cox- 
Table 1 Patient's characteristics

\begin{tabular}{|c|c|c|c|c|c|c|c|c|c|c|c|c|}
\hline \multirow{4}{*}{$\begin{array}{l}\text { Parameters } \\
\text { Age, yrs. }\end{array}$} & \multirow{3}{*}{\multicolumn{2}{|c|}{$\begin{array}{l}\text { Overall } \\
n=198\end{array}$}} & \multicolumn{5}{|c|}{ Increased FM } & \multicolumn{5}{|c|}{ Muscle wasting } \\
\hline & & & \multicolumn{2}{|c|}{ Absent } & \multicolumn{2}{|c|}{ Present } & \multirow{3}{*}{$\begin{array}{l}\boldsymbol{p} \text { value } \\
0.489\end{array}$} & \multirow{2}{*}{\multicolumn{2}{|c|}{$\begin{array}{l}\text { Absent } \\
n=65 \text { (33\%) }\end{array}$}} & \multirow{2}{*}{\multicolumn{2}{|c|}{$\begin{array}{l}\text { Present } \\
n=133(67 \%)\end{array}$}} & \multirow{3}{*}{$\begin{array}{l}\text { p value } \\
0.119\end{array}$} \\
\hline & & & \multicolumn{2}{|c|}{$n=84(42 \%)$} & \multicolumn{2}{|c|}{$n=114(58 \%)$} & & & & & & \\
\hline & 76 & [67-82] & 75 & [67-81] & 76 & [68-82] & & 78 & [67-83] & 74 & [67-81] & \\
\hline Male, n (\%) & 102 & (52) & 48 & (57) & 54 & (47) & 0.224 & 30 & (46) & 72 & (54) & 0.366 \\
\hline Height, cm & 158 & \pm 10 & 159 & \pm 10 & 157 & \pm 10 & 0.370 & 157 & \pm 11 & 158 & \pm 9 & 0.320 \\
\hline Weight, kg & 53 & [47-63] & 49 & [43-56] & 57 & {$[51-67]$} & $<0.001$ & 63 & [51-70] & 51 & [44-58] & $<0.001$ \\
\hline $\mathrm{BMI}, \mathrm{kg} / \mathrm{m}^{2}$ & 22 & [20-24] & 20 & [18-22] & 23 & [22-26] & $<0.001$ & 25 & [23-28] & 20 & [19-23] & $<0.001$ \\
\hline NYHA-FC III, n (\%) & 87 & (44) & 44 & (52) & 43 & (38) & 0.056 & 17 & (26) & 70 & (53) & 0.001 \\
\hline LVEF, \% & 47 & [33-63] & 47 & [31-62] & 48 & [34-64] & 0.342 & 55 & [36-64] & 47 & [32-62] & 0.237 \\
\hline$<40 \%, n(\%)$ & 66 & (33) & 32 & (38) & 34 & (30) & 0.286 & 19 & (29) & 47 & (35) & 0.487 \\
\hline $\mathrm{eGFR}, \mathrm{ml} / \mathrm{min} / 1.73 \mathrm{~cm}^{2}$ & 57 & [38-77] & 55 & [34-80] & 58 & [41-76] & 0.724 & 56 & [45-76] & 59 & [34-78] & 0.997 \\
\hline \multicolumn{13}{|l|}{ DEXA data } \\
\hline ASMI, $\mathrm{kg} / \mathrm{m}^{2}$ & 5.6 & {$[5.0-6.5]$} & 5.5 & {$[4.9-6.3]$} & 5.8 & {$[5.0-6.6]$} & 0.205 & 7.0 & {$[5.8-7.5]$} & 5.1 & {$[4.7-5.9]$} & $<0.001$ \\
\hline PBF, \% & 28.3 & {$[23.6-34.0]$} & 22.8 & [19.6-24.8] & 33.1 & {$[29.2-36.4]$} & $<0.001$ & 30.0 & {$[25.5-35.1]$} & 27.1 & {$[23.0-33.6]$} & 0.025 \\
\hline \multicolumn{13}{|l|}{ Comorbidity } \\
\hline Hypertension & 138 & (70) & 51 & (61) & 87 & (76) & 0.027 & 47 & (72) & 91 & (68) & 0.693 \\
\hline Dyslipidemia & 103 & (52) & 32 & (38) & 71 & (62) & 0.001 & 37 & (57) & 66 & (50) & 0.416 \\
\hline Diabetes & 76 & (38) & 34 & (41) & 42 & (37) & 0.710 & 16 & (25) & 60 & (45) & 0.009 \\
\hline CKD & 98 & (50) & 42 & (50) & 56 & (49) & 1.000 & 31 & (48) & 67 & (50) & 0.839 \\
\hline \multicolumn{13}{|l|}{ Medication } \\
\hline ACE-I or ARB & 91 & (46) & 33 & (39) & 58 & (51) & 0.141 & 34 & (52) & 57 & (43) & 0.271 \\
\hline Beta blocker & 134 & (68) & 58 & (69) & 76 & (67) & 0.841 & 44 & (68) & 90 & (68) & 1.000 \\
\hline Loop diuretics & 122 & (62) & 61 & (73) & 61 & $(54)$ & 0.010 & 34 & (52) & 88 & (66) & 0.084 \\
\hline MRA & 92 & (47) & 44 & (52) & 48 & $(42)$ & 0.198 & 22 & (34) & 70 & (53) & 0.019 \\
\hline Etiology & & & & & & & 0.636 & & & & & 0.011 \\
\hline Cardiomyopathy & 73 & (37) & 31 & (37) & 42 & (37) & & 27 & (42) & 46 & (35) & \\
\hline VHD & 58 & (29) & 21 & (25) & 37 & (33) & & 24 & (37) & 34 & (26) & \\
\hline $\mathrm{HD}$ & 38 & (19) & 18 & (21) & 20 & (18) & & 4 & (6) & 34 & (26) & \\
\hline Others & 29 & (15) & 14 & (17) & 15 & (13) & & 10 & (15) & 19 & (14) & \\
\hline
\end{tabular}

FM fat mass, BMI body mass index, NYHA-FC New York heart association-functional class, LVEF left ventricular ejection fraction

eGFR estimated glomerular filtration ratio, DEXA dual-energy $\mathrm{X}$-ray absorptiometry, $A S M I$ appendicular skeletal muscle mass index, $P B F$ percent body fat, $C K D$ chronic kidney disease, $A C E-I$ angiotensin-converting-enzyme inhibitor, $A R B$ angiotensin II receptor blocker;

MRA mineralocorticoid receptor antagonist, VHD valvular heart disease, IHD ischemic heart disease

Increased percent body fat mass (increased FM) was defined as percent body fat $>25 \%$ in males and $>30 \%$ in females

Muscle wasting, i.e., reduction in skeletal muscle mass, was defined as appendicular skeletal muscle mass index $<7.0 \mathrm{~kg} / \mathrm{m}^{2}$ in males and $<5.4 \mathrm{~kg} / \mathrm{m}^{2}$ in females

proportional hazard model (Supplementary Table 1). In contrast to increased FM, muscle wasting was not selected as an independent determinant of cardiac events in multivariate analysis (Table 3 and Supplementary Table 1).

\section{Discussion}

The relationship between obesity and mortality is highly complex. The concept of the obesity paradox in a general population was derived from results of epidemiological studies showing a U- or J-shaped relationship between BMI-defined obesity and mortality [4-6]. However, this concept has been questioned by the results of a recent meta-analysis [19]. The meta-analysis used data for study subjects who had no smoking history (never smokers) and no chronic diseases at baseline and were followed up for at least 5 years. The results showed that both overweight (BMI, $25.0-29.9 \mathrm{~kg} / \mathrm{m}^{2}$ ) and obesity $\left(\mathrm{BMI}>30 \mathrm{~kg} / \mathrm{m}^{2}\right)$ were associated with increased allcause mortality, while no significant increase in mortality was observed in subjects with lower BMIs [19]. The reason for the apparent discrepancy between the results of the meta-analysis and the results of earlier epidemiological studies is unclear, but difference in baseline characteristics of study subjects is a reasonable explanation. In other words, concurrent chronic diseases and/or smoking habits might have been involved in the increase 

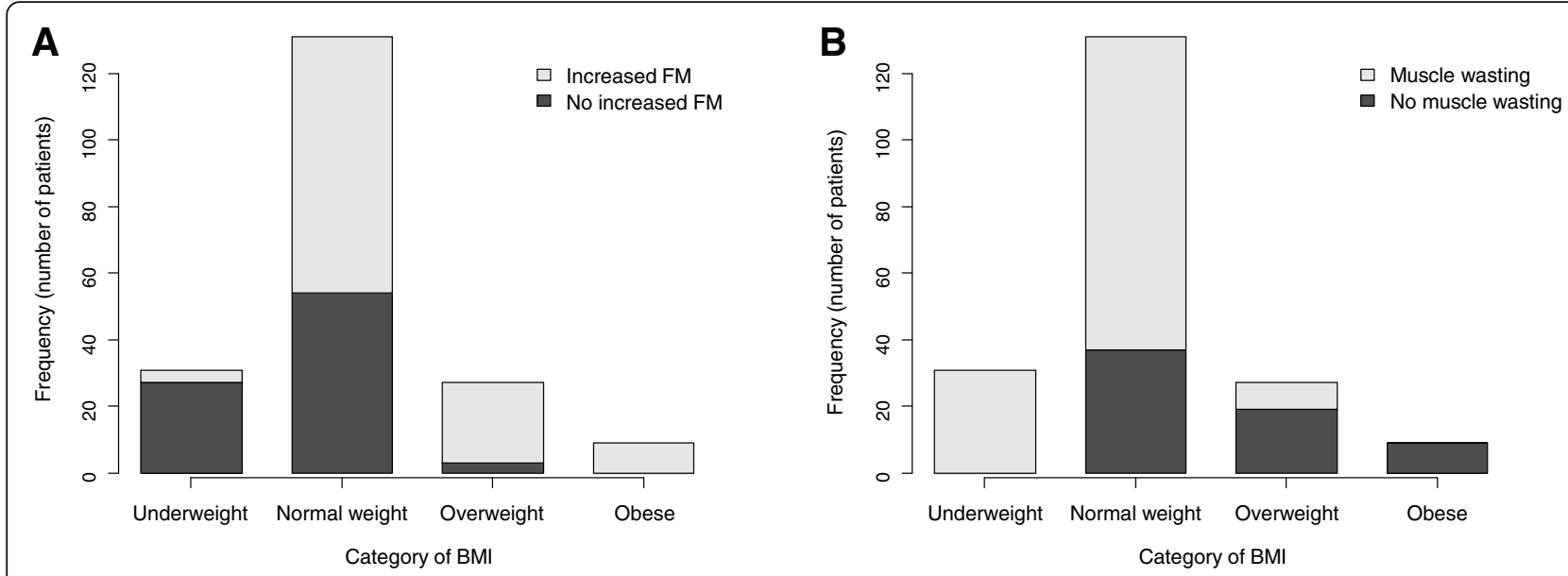

Fig. 1 Proportions of patients with increased body fat mass and patients with muscle wasting in body mass index-based obesity classifications. Body mass index (BMI)-based definition of obesity established by the World Health Organization is as follows: Underweight: BMI $<18.5$, Normal weight: $18.5 \leqq \mathrm{BMI}<25$, Overweight: $25 \leqq \mathrm{BMl}<30$, Obese: $30 \leqq \mathrm{BMI}$. Increased percent body fat mass (increased FM) was defined as dual-energy $\mathrm{X}$ ray absorptiometry-measured percent body fat mass $>25 \%$ in males and $>30 \%$ in females. Muscle wasting was defined by the cut-off values of appendicular skeletal muscle mass index: $<7.00 \mathrm{~kg} / \mathrm{m}^{2}$ in males and $<5.40 \mathrm{~kg} / \mathrm{m}^{2}$ in females

in mortality in subjects with a lowest range BMIs in the epidemiological studies. In fact, this notion is supported by recent findings that reduction in BMI between the first and second hospitalizations for HF was associated with increased risks of subsequent hospitalizations and cardiovascular mortality [20]. Taken together, the results of the earlier studies suggest that chronic diseases underlying BMI reduction as well as obesity have detrimental effects on clinical outcomes, resulting in a Ushaped relationship between BMI and mortality. Whether BMI reduction associated with chronic disease is just a surrogate marker of severity of the disease or whether change in the body mass composition that occurs together with BMI reduction contributes to the mortality remains an important question.

A recent study by Aimo et al. examined the association of estimated percent body fat calculated by prediction equation with prognosis in HF patients to unveil the underlying mechanism of obesity paradox [21]. Although HF patients with the lowest tertile of estimated percent body fat had worse prognosis in that study, the results should be confirmed by using sophisticated assessment of percent body fat. In the present study, we examined compositions of the body by DEXA scans and their relationships with cardiac events during a 180-day follow-up period. Study subjects in the present study were

Table 2 Laboratory data and body composition analysis

\begin{tabular}{|c|c|c|c|c|c|c|c|c|c|c|c|c|}
\hline \multirow{4}{*}{$\begin{array}{l}\text { Parameters } \\
\text { Hemoglobin, g/dl }\end{array}$} & \multirow{2}{*}{\multicolumn{2}{|c|}{ Overall }} & \multicolumn{5}{|c|}{ Increased FM } & \multicolumn{5}{|c|}{ Muscle wasting } \\
\hline & & & \multicolumn{2}{|c|}{ absent } & \multirow{2}{*}{\multicolumn{2}{|c|}{$\begin{array}{l}\text { present } \\
n=114(58 \%)\end{array}$}} & \multirow{3}{*}{$\begin{array}{l}\text { p value } \\
0.249\end{array}$} & \multirow{2}{*}{\multicolumn{2}{|c|}{$\begin{array}{l}\text { absent } \\
n=65(33 \%)\end{array}$}} & \multirow{2}{*}{\multicolumn{2}{|c|}{$\begin{array}{l}\text { present } \\
n=133(67 \%)\end{array}$}} & \multirow{3}{*}{$\begin{array}{l}\mathbf{p} \text { value } \\
0.367\end{array}$} \\
\hline & \multicolumn{2}{|c|}{$n=198$} & \multicolumn{2}{|c|}{$n=84(42 \%)$} & & & & & & & & \\
\hline & 11.8 & [10.4-13.3] & 11.5 & [10.1-13.2] & 12.0 & {$[11.0-13.4]$} & & 11.8 & [10.5-13.5] & 11.6 & [10.4-13.2] & \\
\hline Albumin, g/dl & 3.5 & [3.3-3.8] & 3.5 & {$[3.2-3.7]$} & 3.6 & [3.3-3.9] & 0.322 & 3.6 & [3.4-3.8] & 3.5 & {$[3.2-3.8]$} & 0.154 \\
\hline Creatinine, mg/dl & 1.02 & [0.76-1.50] & 1.04 & {$[0.74-1.60]$} & 0.99 & [0.81-1.33] & 0.755 & 1.03 & [0.82-1.22] & 0.97 & [0.75-1.57] & 0.964 \\
\hline $\mathrm{FPG}, \mathrm{mg} / \mathrm{dl}$ & 91 & [83-102] & 89 & [80-102] & 91 & [84-102] & 0.287 & 90 & [86-97] & 91 & [82-105] & 0.837 \\
\hline Insulin, $\mu \mathrm{IU} / \mathrm{ml}$ & 5.1 & [3.4-7.6] & 3.8 & {$[2.4,6.3]$} & 5.9 & {$[4.4,9.4]$} & $<0.001$ & 5.6 & {$[4.1,8.6]$} & 4.7 & {$[3.1,7.2]$} & 0.056 \\
\hline $\mathrm{TC}, \mathrm{mg} / \mathrm{dl}$ & 162 & [143-186] & 160 & [133-189] & 163 & [145-182] & 0.358 & 161 & [147-186] & 162 & [140-187] & 0.806 \\
\hline $\mathrm{HDL}-\mathrm{C}, \mathrm{mg} / \mathrm{dl}$ & 51 & {$[42-61]$} & 52 & {$[42-64]$} & 50 & {$[41-57]$} & 0.055 & 48 & [40-60] & 52 & [43-62] & 0.363 \\
\hline LDL-C, mg/dl & 90 & [73-111] & 87 & [72-106] & 92 & [75-112] & 0.218 & 90 & [76-111] & 90 & [73-111] & 0.692 \\
\hline $\mathrm{TG}, \mathrm{mg} / \mathrm{dl}$ & 88 & [64-121] & 76 & [59-103] & 98 & [77-123] & $<0.001$ & 91 & [70-123] & 87 & [64-115] & 0.441 \\
\hline NT-proBNP, pg/dl & 1522 & [750-3240] & 2316 & [807-4130] & 1236 & [622-2566] & 0.002 & 1133 & [496-2654] & 1673 & [879-3581] & 0.049 \\
\hline
\end{tabular}

FM fat mass, FPG fasting plasma glucose, TC total cholesterol, LDL-C low density lipoprotein cholesterol, HDL-C high density lipoprotein cholesterol, TG triglyceride, ASMI appendicular skeletal muscle mass index; PBF, percent body fat

Increased percent body fat mass (increased FM) was defined as percent body fat $>25 \%$ in males and $>30 \%$ in females

Muscle wasting, i.e., reduction in skeletal muscle mass, was defined as appendicular skeletal muscle mass index $<7.0 \mathrm{~kg} / \mathrm{m}^{2}$ in males and $<5.4 \mathrm{~kg} / \mathrm{m}^{2}$ in females 


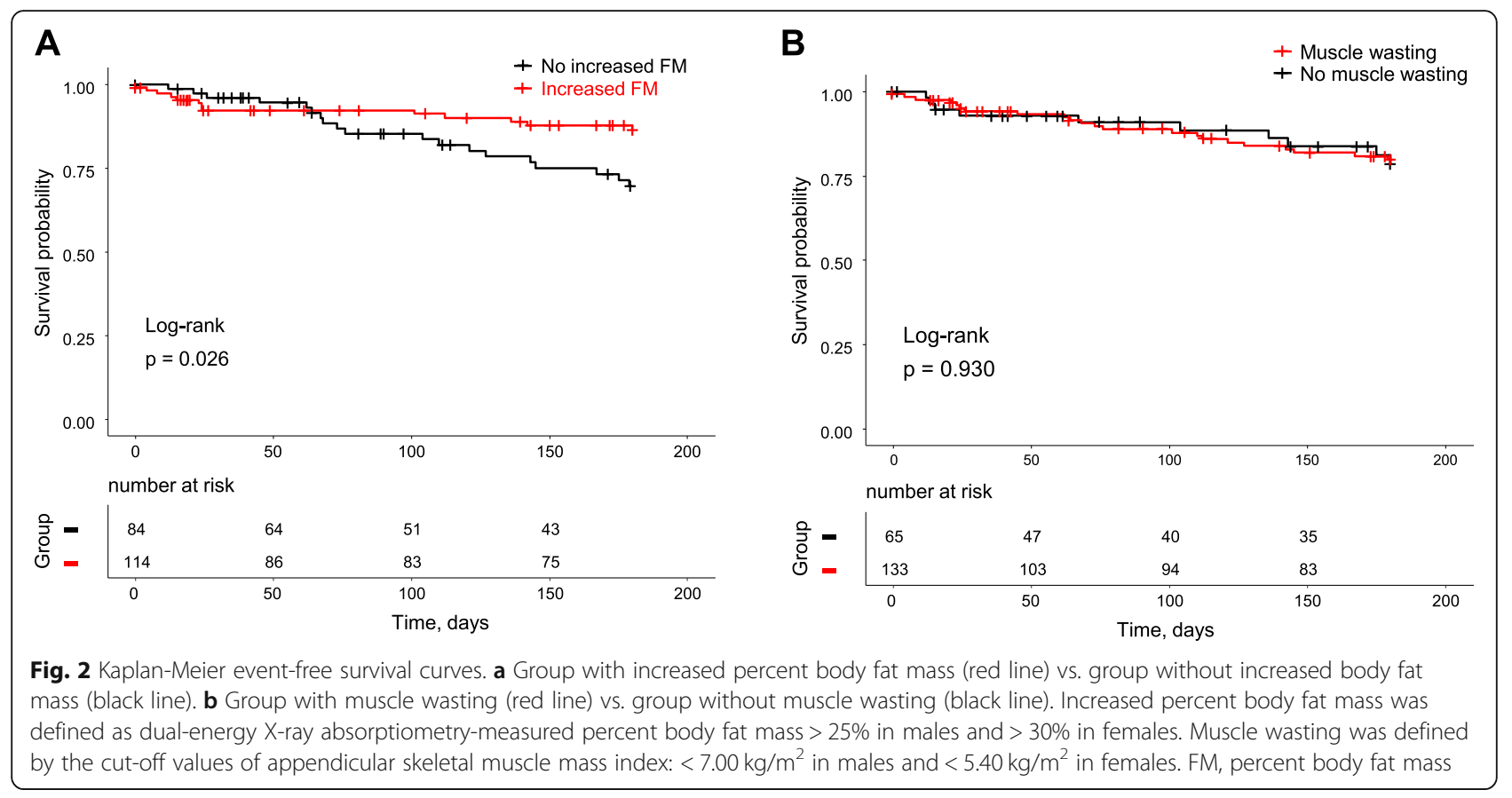

relatively old and mostly classified as non-obese subjects by BMI criteria (Fig. 1). Interestingly, patients with increased FM had a significantly lower cardiac event rate during the follow-up period than did patients without increased FM, though blood biochemistry data were consistent with obesity (i.e., low HDL-cholesterol levels, high triglyceride levels, hyperinsulinemia) (Table 2, Fig. 2a). In contrast, there was no significant difference between cardiac event rates in patients with and those without muscle wasting (Fig. 2b). These results are consistent with the results of a recent study by Thomas et al. using bioelectrical impedance analysis (BIA) for determination of body fat mass in HF outpatients $(n=359)$ [22]. Thomas et al. reported that survival rate was significantly better in patients with body fat mass index $\geq$ the median (i.e., $8.2 \mathrm{~kg} / \mathrm{m}^{2}$ ) than in patients with body fat index $<$ the median [22]. Cox regression multivariate analysis indicated that body fat mass index, but not lean body mass index, was associated with improved survival rate. Despite multiple differences including differences in methods for fat mass determination (DEXA vs. BIA), cutoff levels of fat mass index and presence or absence of gender-specific cutoff levels, the results of the present study and the study by Thomas et al. support the notion that higher percent body fat, but not muscle mass, predicts a lower cardiac event rate in HF patients.

Adipose tissue serves as a critical regulator of systemic energy control [23, 24]. Under a condition in which there is an energy supply, adipose tissue stores excess energy in the form of lipid droplets. Conversely, adipose tissue supplies energy via lipid breakdown in response to a starved condition such as anorexia in HF-induced cachexia. However, the cachexia-induced fat depletion cannot be explained solely by compensatory utilization of adipose tissue for energy production since an increase in energy supply by parenteral nutrition does not reverse the cachexic state [25]. Chronic diseases including chronic HF provoke systemic inflammation induced by innate immune signaling $[26,27]$, leading to inappropriate degradation of adipose tissue [11,28]. Catecholamine excess and hormone imbalance are aggravative factors in this process $[11,29]$. Importantly, innate immune signaling in HF is upregulated in an HF severitydependent manner [30-32], and recent studies have shown that inflammatory diseases as well as malnutrition and HF are closely associated with muscle wasting [33-36]. Albeit there being shared signal pathways leading to fat depletion and muscle wasting, reduction in body fat is not necessarily concordant with reduction in skeletal muscle mass in the clinical course of HF [11]. In the present study subjects, the proportion of patients with muscle wasting was higher than that of patients with no increased FM (67\% vs. $42 \%)$. When patients were divided into two groups by ASMI, the group with muscle wasting had slightly smaller body fat mass (median, $27.1 \%$ vs. $30.0 \%$ ). On the other hand, when patients were divided into two groups by a cutoff level of increased FM, there was no significant difference in skeletal muscle mass (median, 5.8 vs. $5.5 \mathrm{~kg} / \mathrm{m}^{2}$ ) between the two groups. These findings suggest that distinct mechanisms are operative for preservation of adipose tissue and 


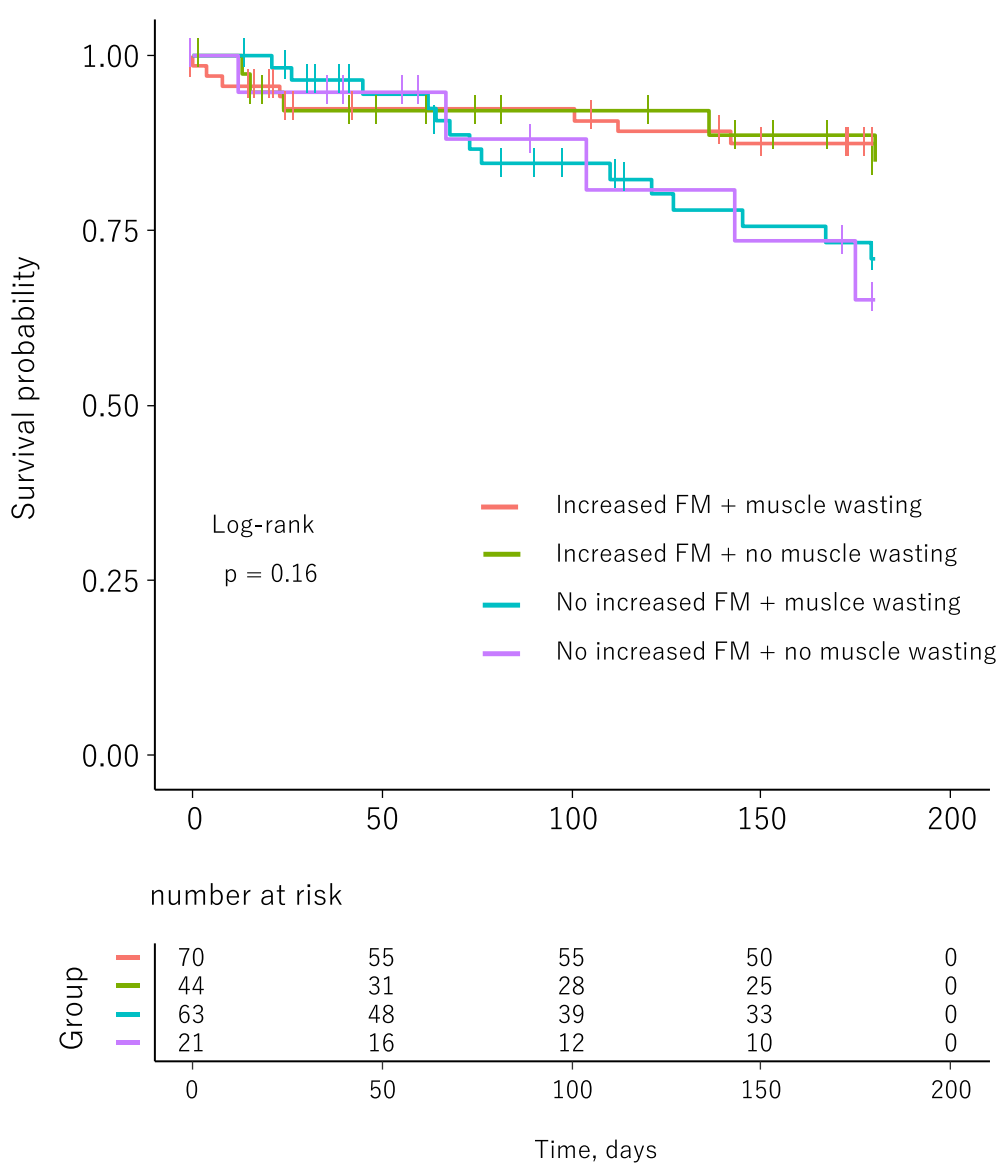

Fig. 3 Kaplan-Meier event-free survival curves for each body composition category. Increased percent body fat mass was defined as dual-energy X-ray absorptiometry-measured percent body fat mass $>25 \%$ in males and $>30 \%$ in females. Muscle wasting was defined by the cut-off values of appendicular skeletal muscle mass index: $<7.00 \mathrm{~kg} / \mathrm{m}^{2}$ in males and $<5.40 \mathrm{~kg} / \mathrm{m}^{2}$ in females. FM, percent body fat mass

preservation of skeletal muscle mass, while skeletal muscle preservation is partly dependent on the adipose tissue mass. In fact, starvation induces depletion of both skeletal muscle and body fat, and moderate to severe obesity potentially induces muscle wasting by fat-induced systemic inflammation [37, 38]. Nevertheless, a significant association between cardiac events and preserved body fat mass (Fig. 2) supports the notion that a favorable energy storage/supply balance in adipose tissue contributes to prevention of cardiac events.

Table 3 Univariate and Multivariate analyses by Cox-proportional hazards model

\begin{tabular}{|c|c|c|c|c|c|c|c|c|c|c|c|c|}
\hline \multirow[t]{3}{*}{ Parameters } & \multirow{2}{*}{\multicolumn{3}{|c|}{ Univariate model }} & \multicolumn{9}{|c|}{ Multivariate model } \\
\hline & & & & \multicolumn{3}{|c|}{ model 1} & \multicolumn{3}{|c|}{ model 2} & \multicolumn{3}{|c|}{ model 3} \\
\hline & HR & $95 \% \mathrm{Cl}$ & $p$ value & HR & $95 \% \mathrm{Cl}$ & $p$ value & HR & $95 \% \mathrm{Cl}$ & $p$ value & $\mathrm{HR}$ & $95 \% \mathrm{Cl}$ & $p$ value \\
\hline Age, yrs & 1.003 & $(0.978-1.029)$ & 0.808 & 1.001 & $(0.976-1.028)$ & 0.912 & 0.990 & $(0.963-1.017)$ & 0.460 & 0.993 & $(0.966-1.021)$ & 0.616 \\
\hline Sex, male & 0.848 & $(0.424-1.697)$ & 0.641 & 0.852 & $(0.422-1.717)$ & 0.653 & 0.650 & $(0.320-1.320)$ & 0.233 & 0.787 & $(0.374-1.655)$ & 0.528 \\
\hline Increased FM, yes & 0.457 & $(0.225-0.925)$ & 0.030 & 0.450 & $(0.221-0.916)$ & 0.028 & 0.458 & $(0.223-0.938)$ & 0.033 & 0.582 & $(0.275-1.233)$ & 0.158 \\
\hline Muscle wasting, yes & 0.967 & $(0.458-2.043)$ & 0.930 & 0.880 & $(0.413-1.877)$ & 0.741 & 0.868 & $(0.391-1.925)$ & 0.728 & 0.837 & $(0.369-1.896)$ & 0.669 \\
\hline $\mathrm{eGFR}, \mathrm{ml} / \mathrm{min} / 1.73 \mathrm{~m} 2$ & 0.978 & (0.964-0.993) & 0.004 & & & & 0.978 & $(0.962-0.993)$ & 0.005 & 0.986 & $(0.969-1.004)$ & 0.122 \\
\hline Diabetes, yes & 1.560 & $(0.779-3.126)$ & 0.210 & & & & 1.190 & $(0.563-2.517)$ & 0.649 & 1.108 & $(0.511-2.401)$ & 0.794 \\
\hline NT-proBNP, pg/ml & 1.884 & $(1.391-2.552)$ & $<0.001$ & & & & & & & 1.488 & $(1.030-2.150)$ & 0.034 \\
\hline
\end{tabular}


An increase in fat mass induces systemic inflammation including cytokine release, leading to pathological/functional myocardial dysfunction $[38,39]$. In addition to the absolute mass of body fat, fat distribution is also tightly linked to the development and progression of metabolic diseases and HF [40, 41]. In a clinical setting, waist circumference has been applied as a surrogate marker of visceral fat mass, which is one of the diagnostic criteria of metabolic syndrome [42, 43]. The contribution of an increase in abdominal fat mass to the progression of heart failure was supported by the results of a recent study showing that abdominal obesity, defined as waist circumferences of $>102 \mathrm{~cm}$ in men and $>88 \mathrm{~cm}$ in women, in patients with HFpEF was significantly associated with an increased risk of all-cause mortality [40]. In addition, obesity and diseases characterized by chronic inflammation lead to epicardial fat accumulation [41]. There is evidence indicating that epicardial fat plays a detrimental role in the pathophysiology of HF. Epicardial fat thickness is closely associated with the extent of myocardial fibrosis, leading to myocardial dysfunction $[44,45]$. Furthermore, accumulation of epicardial fat induces systemic inflammation, possibly contributing to further fat accumulation. Unfortunately, we could not include data for abdominal fat and data for epicardial fat in the present analyses because of technical limitations and the retrospective nature of the study.

Circulating natriuretic peptide (NP) level is an established marker of HF prognosis [46, 47]. Venous blood level of NP is positively correlated with the extent of myocardial stretch, which is usually reflected by increased filling pressure of the ventricle. In addition to such a ventricular pressure-dependent release of NP into the circulation, several regulatory mechanisms of circulating levels of NP have been reported. Levels of NPs, especially NT-proBNP, are elevated by renal failure since NPs are mainly cleared from circulating blood by renal excretion [48]. Hyperinsulinemia, frequently seen in obese patients, is associated with lower NT-proBNP levels $[49,50]$. Circulating levels of proinflammatory cytokines such as TNF- $\alpha$ and IL-1 $\beta$, which are pronouncedly increased in a cachexic state, increase production of brain natriuretic peptide from cardiomyocytes [51]. Interestingly, NP has recently been reported to significantly stimulate lipolysis [52]. Thus, there is the possibility that marked elevation of NP level in cachexic HF patients exerts a detrimental effect on HF by acceleration of lipolysis, resulting in reduction of body fat mass, though protective effects of NPs on cardiovascular and renal functions have already been characterized. In fact, the prognostic impact of low body fat mass in the present study was lost by the inclusion of NT-proBNP into the Cox proportional hazard model (Table 3). Furthermore, a negative correlation between percent body fat and NT-proBNP levels was found (Fig. 4), suggesting an interaction of body fat mass level and level of NTproBNP in HF patients. On the other hand, the prognostic impact of increased FM was also lost by the inclusion of NYHA functional class into the Cox proportional hazard model (Supplementary Table 1), suggesting that HF severity overcomes percent body fat in the prediction of short-term prognosis in HF patients. These findings need to be confirmed in a large population-based study of HF.

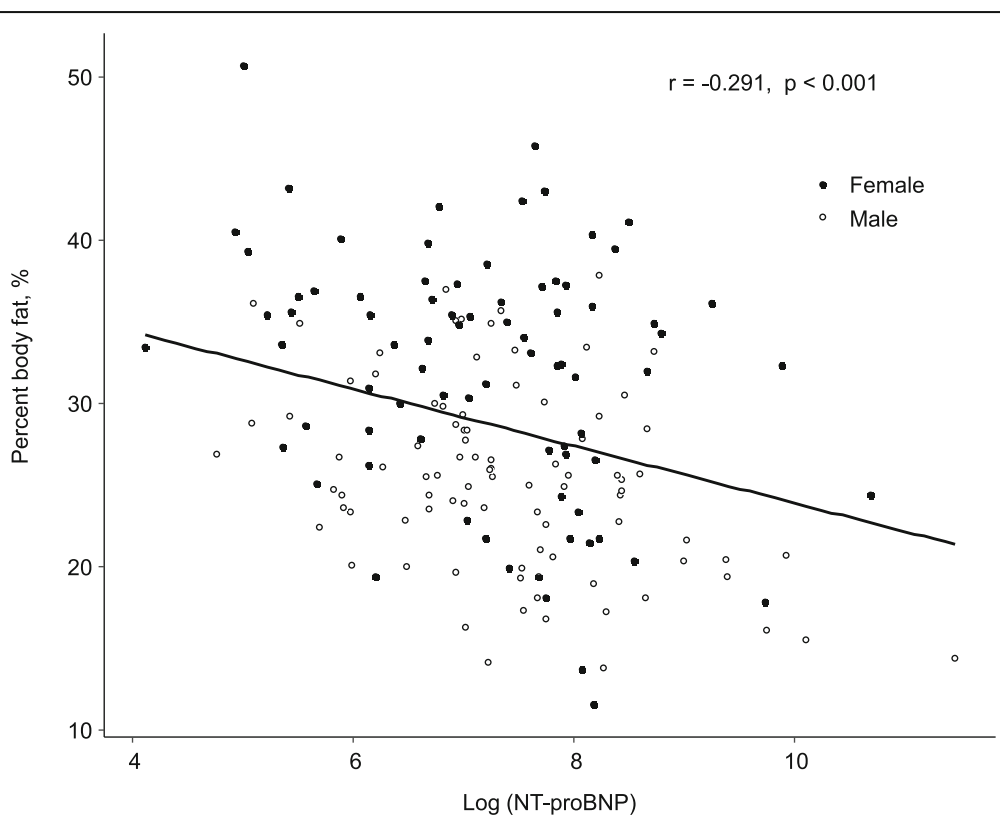

Fig. 4 Association between percent body fat and NT-proBNP levels 
Fat mass, muscle mass, and bone mineral content are reduced as cachexic conditions progress [13]. Our recent study reported that presence of osteoporosis assessed during hospital stay is an independent predictor of adverse events after discharge and fat mass index was closely associated with the extent of osteoporosis [53]. Result of a recent study showed that muscle wasting is an independent predictor of mortality in stable ambulatory HF patients [54]. Taken together with findings of the present study, muscle wasting may be an early marker for HF progression, whereas reduction in fat mass and bone mineral content may serve as a marker of cachexia. Importantly, adipose tissue supplies energy via lipid breakdown in response to a starved condition such as anorexia in HF-induced cachexia, which might play a role in reduced cardiac events at the advanced stage of HF. A potential therapeutic approach targeting cachexia including fat depletion is a nutritional intervention since results of our very recent study showed that energy intake during hospital stay is a strong predictor of all-cause mortality even in elderly HF patients [55]. However, an increase in energy supply by parenteral nutrition did not reverse the cachexic state [25]. Therefore, further analyses are needed to demonstrate the complex relationship between fat mass and prognosis.

There are limitations in the present study. First, since this study was a retrospective observational study using a small number of patients in a single center, there might have been selection bias in study subjects. Importantly, the present study might have insufficient statistical power for detection of effects of fat/muscle mass on cardiac events among the groups with different etiologies of heart failure, e.g., HFrEF vs. HFpEF, though results of post-host analyses showed that prognostic impact of increased FM tended to be found in patients with HFrEF and with heart failure with mid-range ejection fraction (Supplementary Figure 1-2 and Supplementary Table 2). Second, sarcopenic obesity, i.e. coexistence of obesity and sarcopenia, is frequently observed in HF patients with $\mathrm{HFpEF}$, which is a risk factor of hospitalization and death $[56,57]$. Small number of patients with HFpEF in the present study (45/198) might be responsible for loss of prognostic effect of sarcopenic obesity as shown by the data: presence of muscle wasting had no effects on cardiac event rates also in HF patients with increased FM (Fig. 3). In addition, muscle strength, a criterion of sarcopenia, was not analyzed in the present study, which might contribute to underestimation of well-known prognostic impact of sarcopenia in this study subjects $[18,58]$. Therefore, further analyses are needed to demonstrate the impact of sarcopenic obesity on cardiac event rates in our study population. Third, the patients enrolled in the present study were patients who were admitted to our institute for diagnosis and/or treatment of
HF. Patients who were admitted for acute decompensation heart failure were also included. Although assessment of body composition was performed after the relief of worsening HF, the findings in the present study may not be extrapolated to ambulatory HF patients. Finally, previous studies repeatedly showed race/regiondependent variation in body composition [59, 60]. Thus, the results of the present study may not necessarily be applicable to other ethnicities.

\section{Conclusions}

Increased body fat mass, but not appendicular skeletal muscle mass, predicts a lower cardiac event rate after hospital discharge in non-obese HF patients.

\section{Supplementary Information}

The online version contains supplementary material available at https://doi. org/10.1186/s12877-020-01950-9.

\section{Additional file 1.}

\section{Abbreviations}

BMI: Body mass index; HF: Heart failure; LVEF: Left ventricular ejection fraction; FM: Fat mass; IQR: Interquartile range; HFrEF: Heart failure with reduced ejection fraction; HFpEF: Heart failure with preserved ejection fraction; DEXA: Dual-energy X-ray absorptiometry; NYHA: New York Heart Association; ASM: Appendicular skeletal muscle mass; ASMI: Appendicular skeletal muscle mass index; eGFR: Estimated glomerular filtration rate; NTproBNP: pro B-type natriuretic peptide; CKD: Chronic kidney disease; NP: Natriuretic peptide

\section{Acknowledgements}

Not applicable.

\section{Authors' contributions}

All authors have read and approved the manuscript. In addition, we confirm that all listed authors meet the authorship criteria and that all authors are in agreement with the content of the manuscript. KO, TY, SK, AH, and TM designed the study. KO, TY, SK, HK, SH, KS, TI1, YT, RN, MK, NN, TF, RN, TI2, AW, and $\mathrm{RH}$ collected the patients' data. KO, TY, SK, HK, and TM analyzed and discussed data. KO, TY and SK performed statistical analyses. KO, TY, and TM drafted the manuscript. TI1 corresponds to Takuya Inoue.

\section{Funding}

This study was supported by Grant-in-Aid for Young Scientists (Katano S) from the Japan Society for the Promotion of Science KAKENHI Grant Number JP18K17677, Tokyo, Japan.

The funding body played no role in the design of the study and collection, analysis, and interpretation of data and in writing the manuscript.

\section{Availability of data and materials}

The datasets generated and/or analyzed during the current study are not publicly available because a research agreement from all authors is required for data sharing, but are available from the corresponding author on reasonable request.

\section{Ethics approval and consent to participate}

This study was reviewed and approved by the Clinical Investigation Ethics Committee of Sapporo Medical University Hospital (Number 302-243). Given the retrospective and anonymized nature of this study, the Clinical Investigation Ethics Committee of Sapporo Medical University Hospital waived the need for informed consent from the study participants. 


\section{Competing interests}

We declare that we have no competing interests.

\begin{abstract}
Author details
'Department of Cardiovascular, Renal and Metabolic Medicine, Sapporo Medical University School of Medicine, South-1, West-16, Chuo-ku, Sapporo 060-8543, Japan. ${ }^{2}$ Department of Cardiology, Hokkaido Cardiovascular Hospital, Sapporo, Japan. ${ }^{3}$ Division of Rehabilitation, Sapporo Medical University Hospital, Sapporo, Japan. ${ }^{4}$ Department of Public Health, Sapporo Medical University School of Medicine, Sapporo, Japan. ${ }^{5}$ Division of Hospital Pharmacy, Sapporo Medical University Hospital, Sapporo, Japan. ${ }^{6}$ Division of Nursing, Sapporo Medical University Hospital, Sapporo, Japan. 'Division of Health Care Administration and Management, Sapporo Medical University School of Medicine, Sapporo, Japan.
\end{abstract}

Received: 3 August 2020 Accepted: 8 December 2020

Published online: 06 January 2021

\section{References}

1. Kenchaiah S, Evans JC, Levy D, Wilson PW, Benjamin EJ, Larson MG, et al. Obesity and the risk of heart failure. N Engl J Med. 2002;347:305-13.

2. Carbone S, Lavie CJ, Arena R. Obesity and heart failure: focus on the obesity paradox. Mayo Clin Proc. 2017;92:266-79.

3. Doehner W, Clark A, Anker SD. The obesity paradox: weighing the benefit Eur Heart J. 2010;31:146-8.

4. Adams KF, Schatzkin A, Harris TB, Kipnis V, Mouw T, Ballard-Barbash R, et al. Overweight, obesity, and mortality in a large prospective cohort of persons 50 to 71 years old. N Engl J Med. 2006;355:763-78.

5. Prospective Studies Collaboration, Whitlock G, Lewington S, Sherliker P, Clarke R, Emberson J, et al. Body-mass index and cause-specific mortality in 900000 adults: collaborative analyses of 57 prospective studies. Lancet. 2009:373:1083-96.

6. Flegal KM, Kit BK, Orpana H, Graubard BI. Association of all-cause mortality with overweight and obesity using standard body mass index categories: a systematic review and meta-analysis. JAMA. 2013;309:71-82.

7. Nagarajan V, Kohan L, Holland E, Keeley EC, Mazimba S. Obesity paradox in heart failure: a heavy matter. ESC Heart Fail. 2016:3:227-34.

8. Yoo HJ. Body mass index and mortality. J Obes Metab Syndr. 2017;26:3-9.

9. Padwal R, McAlister FA, McMurray JJ, Cowie MR, Rich M, Pocock S, et al. The obesity paradox in heart failure patients with preserved versus reduced ejection fraction: a meta-analysis of individual patient data. Int J Obes. 2014; 38:1110-4.

10. Kapoor JR, Heidenreich PA. Obesity and survival in patients with heart failure and preserved systolic function: a U-shaped relationship. Am Heart J. 2010;159:75-80.

11. von Haehling S, Ebner N, Dos Santos MR, Springer J, Anker SD. Muscle wasting and cachexia in heart failure: mechanisms and therapies. Nat Rev Cardiol. 2017:14:323-41.

12. Anker SD, Ponikowski P, Varney S, Chua TP, Clark AL, Webb-Peploe KM, et al. Wasting as independent risk factor for mortality in chronic heart failure. Lancet. 1997;349:1050-3.

13. Anker SD, Clark AL, Teixeira MM, Hellewell PG, Coats AJ. Loss of bone mineral in patients with cachexia due to chronic heart failure. Am J Cardiol. 1999:83:612-5 A10

14. Buckinx F, Landi F, Cesari M, Fielding RA, Visser M, Engelke $K$, et al. Pitfalls in the measurement of muscle mass: a need for a reference standard. J Cachexia Sarcopenia Muscle. 2018;9:269-78.

15. Tsutsui $H$, Isobe $M$, Ito H, Ito H, Okumura K, Ono M, et al. JCS 2017/JHFS 2017 guideline on diagnosis and treatment of acute and chronic heart failure - digest version. Circ J. 2019;83:2084-184.

16. Katano S, Yano T, Ohori K, Nagano N, Honma S, Shimomura K, et al. Novel prediction equation for appendicular skeletal muscle mass estimation in patients with heart failure: potential application in daily clinical practice. Eur J Prev Cardiol. 2020; Online ahead of print

17. Ohno M, Ikeda Y. "Chukonennihonjin ni okeru taishibouritu, BMI to yuubyoushisuu tono kanren" The association of percent body fat and BMI with prevalence rates in the middle-aged Japanese. J Japan Soc Stud Obesity. 1998:4:60 (in Japanese).

18. Chen LK, Liu LK, Woo J, Assantachai P, Auyeung TW, Bahyah KS, et al. Sarcopenia in Asia: consensus report of the Asian working Group for Sarcopenia. J Am Med Dir Assoc. 2014;15:95-101.
19. Global BMI Mortality Collaboration, Di Angelantonio E, Bhupathiraju SN, Wormser D, Gao P, Kaptoge S, et al. Body-mass index and all-cause mortality: individual-participant-data meta-analysis of 239 prospective studies in four continents. Lancet. 2016;388:776-86.

20. Nishikido T, Oyama JI, Nagatomo D, Node K. A reduction of BMI predicts the risk of rehospitalization and cardiac death in non-obese patients with heart failure. Int J Cardiol. 2019;276:166-70.

21. Aimo A, Januzzi JL Jr, Vergaro G, Clerico A, Latini R, Meessen J, et al. Revisiting the obesity paradox in heart failure: per cent body fat as predictor of biomarkers and outcome. Eur J Prev Cardiol. 2019;26:1751-9.

22. Thomas E, Gupta PP, Fonarow GC, Horwich TB. Bioelectrical impedance analysis of body composition and survival in patients with heart failure. Clin Cardiol. 2019:42:129-35.

23. Choe SS, Huh JY, Hwang IJ, Kim JI, Kim JB. Adipose tissue remodeling: its role in energy metabolism and metabolic disorders. Front Endocrinol (Lausanne). 2016;7:30.

24. Birsoy K, Festuccia WT, Laplante M. A comparative perspective on lipid storage in animals. J Cell Sci. 2013;126:1541-52.

25. Evans WJ, Morley JE, Argilés J, Bales C, Baracos V, Guttridge D, et al. Cachexia: a new definition. Clin Nutr. 2008;27:793-9.

26. Frantz S, Falcao-Pires I, Balligand JL, Bauersachs J, Brutsaert D, Ciccarelli M, et al. The innate immune system in chronic cardiomyopathy: a European Society of Cardiology (ESC) scientific statement from the working group on myocardial function of the ESC. Eur J Heart Fail. 2018;20:445-59.

27. Mann DL. The emerging role of innate immunity in the heart and vascular system: for whom the cell tolls. Circ Res. 2011;108:1133-45.

28. Porporato PE. Understanding cachexia as a cancer metabolism syndrome. Nat Rev Cardiol. 2017;14:323-41.

29. Agustsson T, Rydén M, Hoffstedt J, van Harmelen V, Dicker A, Laurencikiene $J$, et al. Mechanism of increased lipolysis in cancer cachexia. Cancer Res. 2007;67:5531-7.

30. Testa M, Yeh M, Lee P, Fanelli R, Loperfido F, Berman JW, et al. Circulating levels of cytokines and their endogenous modulators in patients with mild to severe congestive heart failure due to coronary artery disease or hypertension. J Am Coll Cardiol. 1996;28:964-71.

31. Nozaki N, Yamaquchi S, Shirakabe M, Nakamura H, Tomoike H. Soluble tumor necrosis factor receptors are elevated in relation to severity of congestive heart failure. Jpn Circ J. 1997;61:657-64.

32. Petretta M, Condorelli GL, Spinelli L, Scopacasa F, de Caterina M, Leosco D, et al. Circulating levels of cytokines and their site of production in patients with mild to severe chronic heart failure. Am Heart J. 2000;140:E28.

33. Anker SD, Coats AJ, Morley JE, Rosano G, Bernabei R, von Haehling S, et al. Muscle wasting disease: a proposal for a new disease classification. J Cachexia Sarcopenia Muscle. 2014;5:1-3.

34. Dudgeon D, Baracos VE. Physiological and functional failure in chronic obstructive pulmonary disease, congestive heart failure and cancer: a debilitating intersection of sarcopenia, cachexia and breathlessness. Curr Opin Support Palliat Care. 2016;10:236-41

35. Fülster S, Tacke M, Sandek A, Ebner N, Tschöpe C, Doehner W, et al. Muscle wasting in patients with chronic heart failure: results from the studies investigating comorbidities aggravating heart failure (SICA-HF). Eur Heart J. 2013;34:512-9.

36. Hajahmadi M, Shemshadi S, Khalilipur E, Amin A, Taghavi S, Maleki M, et al. Muscle wasting in young patients with dilated cardiomyopathy. J Cachexia Sarcopenia Muscle. 2017;8:542-8.

37. Abete I, Konieczna J, Zulet MA, Galmés-Panades AM, Ibero-Baraibar I, Babio $\mathrm{N}$, et al. Association of lifestyle factors and inflammation with sarcopenic obesity: data from the PREDIMED-plus trial. J Cachexia Sarcopenia Muscle. 2019;10:974-84

38. Upadhya B, Haykowsky MJ, Eggebeen J, Kitzman DW. Sarcopenic obesity and the pathogenesis of exercise intolerance in heart failure with preserved ejection fraction. Curr Heart Fail Rep. 2015;12:205-14.

39. Nishida K, Otsu K. Inflammation and metabolic cardiomyopathy. Cardiovasc Res. 2017;113:389-98.

40. Tsujimoto T, Kajio H. Abdominal obesity is associated with an increased risk of all-cause mortality in patients with HFpEF. J Am Coll Cardiol. 2017;70: 2739-49.

41. Packer M. Epicardial adipose tissue may mediate deleterious effects of obesity and inflammation on the myocardium. J Am Coll Cardiol. 2018;71: 2360-72.

42. Expert Panel on Detection, Evaluation, and Treatment of High Blood Cholesterol in Adults. Executive Summary of The Third Report of The 
National Cholesterol Education Program (NCEP) Expert Panel on Detection, Evaluation, And Treatment of High Blood Cholesterol In Adults (Adult Treatment Panel III). JAMA. 2001;285:2486-97.

43. Alberti KG, Zimmet PZ. Definition, diagnosis and classification of diabetes mellitus and its complications. Part 1: diagnosis and classification of diabetes mellitus provisional report of a WHO consultation. Diabet Med. 1998;15:539-53.

44. Wu CK, Tsai HY, Su MM, Wu YF, Hwang JJ, Lin JL, et al. Evolutional change in epicardial fat and its correlation with myocardial diffuse fibrosis in heart failure patients. J Clin Lipidol. 2017;11:1421-31.

45. Patel VB, Mori J, McLean BA, Basu R, Das SK, Ramprasath T, et al. ACE2 deficiency worsens Epicardial adipose tissue inflammation and cardiac dysfunction in response to diet-induced obesity. Diabetes. 2016;65:85-95.

46. Silver MA, Maisel A, Yancy CW, McCullough PA, Burnett JC Jr, Francis GS, et al. BNP consensus panel 2004: a clinical approach for the diagnostic, prognostic, screening, treatment monitoring, and therapeutic roles of natriuretic peptides in cardiovascular diseases. Congest Heart Fail. 2004;10: $1-30$

47. Francis GS, Felker GM, Tang WH. A test in context: critical evaluation of natriuretic peptide testing in heart failure. J Am Coll Cardiol. 2016;67:330-7.

48. Colbert G, Jain N, de Lemos JA, Hedayati SS. Utility of traditional circulating and imaging-based cardiac biomarkers in patients with predialysis CKD. Clin J Am Soc Nephrol. 2015;10:515-29.

49. Trevisan R, Fioretto P, Semplicini A, Opocher G, Mantero F, Rocco S, et al. Role of insulin and atrial natriuretic peptide in sodium retention in insulintreated IDDM patients during isotonic volume expansion. Diabetes. 1990;39: 289-98.

50. Abouchacra S, Baines AD, Zinman B, Skorecki KL, Logan AG. Insulin blunts the natriuretic action of atrial natriuretic peptide in hypertension. Hypertension. 1994;23:1054-8.

51. Ma KK, Ogawa T, de Bold AJ. Selective upregulation of cardiac brain natriuretic peptide at the transcriptional and translational levels by pro-inflammatory cytokines and by conditioned medium derived from mixed lymphocyte reactions via p38 MAP kinase. J Mol Cell Cardiol. 2004;36:505-13.

52. Bordicchia M, Liu D, Amri EZ, Ailhaud G, Dessi-Fulgheri P, Zhang C, et al. Cardiac natriuretic peptides act via p38 MAPK to induce the brown fat thermogenic program in mouse and human adipocytes. J Clin Invest. 2012; 122:1022-36.

53. Katano S, Yano T, Tsukada T, Kouzu H, Honma S, Inoue T, et al. Clinical risk factors and prognostic impact of osteoporosis in patients with chronic heart failure. Circ J. 2020. https://doi.org/10.1253/circj.CJ-20-0593 Online ahead of print.

54. von Haehling S, Garfias Macedo T, Valentova M, Anker MS, Ebner N, Bekfani $\mathrm{T}$, et al. Muscle wasting as an independent predictor of survival in patients with chronic heart failure. J Cachexia Sarcopenia Muscle. 2020;11:1242-9.

55. Katano S, Yano T, Kouzu H, Ohori K, Shimomura K, Honma S, et al. Energy intake during hospital stay predicts all-cause mortality after discharge independently of nutritional status in elderly heart failure patients. Clin Res Cardiol. 2020; in press.

56. Kirkman DL, Bohmke N, Billingsley HE, Carbone S. Sarcopenic obesity in heart failure with preserved ejection fraction. Front Endocrinol (Lausanne). 2020;11:558271.

57. Carbone S, Billingsley HE, Rodriguez-Miguelez P, Kirkman DL, Garten R, Franco RL, et al. Lean mass abnormalities in heart failure: the role of sarcopenia, Sarcopenic obesity, and Cachexia. Curr Probl Cardiol. 2020;45: 100417

58. Carbone S, Kirkman DL, Garten RS, Rodriguez-Miguelez P, Artero EG, Lee DC, et al. Muscular strength and cardiovascular disease: AN UPDATED STATE-OFTHE-ART NARRATIVE REVIEW. J Cardiopulm Rehabil Prev. 2020;40:302-9.

59. Gerace L, Aliprantis A, Russell M, Allison DB, Buhl KM, Wang J, et al. Skeletal differences between black and white men and their relevance to body composition estimates. Am J Hum Biol. 1994;6:255-62.

60. Ortiz O, Russell M, Daley TL, Baumgartner RN, Waki M, Lichtman S, et al. Differences in skeletal muscle and bone mineral mass between black and white females and their relevance to estimates of body composition. Am J Clin Nutr. 1992;55:8-13.

\section{Publisher's Note}

Springer Nature remains neutral with regard to jurisdictional claims in published maps and institutional affiliations.

Ready to submit your research? Choose BMC and benefit from:

- fast, convenient online submission

- thorough peer review by experienced researchers in your field

- rapid publication on acceptance

- support for research data, including large and complex data types

- gold Open Access which fosters wider collaboration and increased citations

- maximum visibility for your research: over $100 \mathrm{M}$ website views per year

At BMC, research is always in progress.

Learn more biomedcentral.com/submissions 